ISSN 1112-9867

\title{
NATURAL BIOACTIVE COMPOUNDS: ANTIBIOTICS
}

\author{
N. Khandan Dezfully ${ }^{1,2, *}$ and A. Heidari ${ }^{3}$ \\ ${ }^{1}$ Department of Studies in Microbiology, University of Mysore, Manasagangotri, Mysore- \\ 570006, Karnataka, India \\ ${ }^{2}$ Young Researchers and Elite Club, Karaj Branch, Islamic Azad University, Alborz, Iran \\ ${ }^{3}$ Department of Emergency Medicine, Shahid Beheshti Medical University, Tehran, Iran
}

Published online: 13 June 2016

\begin{abstract}
Antibiotics are powerful therapeutic agents that are produced by diverse living organisms. Over the last several decades, natural bioactive products particularly antibiotics have continued to play a significant role in drug discovery and has expanded the process for developing drugs with high degree of therapeutic index and specific action. Today, there is an alarming deficiency of new antibiotics in the pharmaceutical industry that could be due to the emergence of antibiotic resistance properties of some pathogens, toxicity and undesirable side effects of some used antibiotics. Although much progress has been performed in the field of chemical synthesis and engineered biosynthesis of antimicrobial compounds. Hence, there is a need in approach for novel antibiotics and research to improve the safety as well as therapeutic efficiency of the discovered bioactive compounds as part of the strategy to control the emerging drug-resistant pathogens in research programme around the world. This article reviews the history of antibiotics, different types of antibiotics, mechanisms of antibiotic action and new challenges in antibiotics.
\end{abstract}

KEYWORDS: Secondary metabolites; microorganisms; Actinomycetes; Antimicrobial activity; Pharmaceuticals.

\footnotetext{
Author Correspondence, e-mail: nooshinkhandan@gmail.com

doi: http://dx.doi.org/10.4314/jfas.8vi2s.81
} 


\section{INTRODUCTION}

Antibiotics are the most important class of natural bioactive compounds (as a secondary metabolites) with low molecular weight (MW 3000) which are produced by or derived from diverse organisms (bacteria, actinomycetes, fungi, algae, lichens, green plants, etc.) by fermentation, which have the capacity of inhibiting or terminating total metabolic cell activity [1-3]. The word antibiotic came from the Greek word antibiosis (Gr. anti, "against"; bios, "life") a term coined by Louis Pasteur's pupil Paul Vuillemin in 1889. They are defined as a chemical substance that either inhibits the growth of or destroys microorganisms. These natural compounds can show either antimicrobial (antibacterial, antifungal, antiprotozoal), antiviral and antitumor activities. They considered as 'bioactive compounds' because they have biological activity. Antimicrobial compounds are classified based on the range of effectiveness in to broad spectrum that are (effective against many types of microorganism) and narrow spectrum (effective against a limited group of microorganism) [1]. Antibiotics have been used in a variety of industries such as pharmaceuticals [4] and food industry, especially in the field of prebiotics and probiotics [3,5]. This review outlines the history of antibiotics, different types of antibiotics, the mechanism of antibiotics action and new challenges in antibiotics.

\section{HISTORY OF ANTIBIOTICS}

Since the beginning of human suffering from infectious diseases caused by microorganisms, the search for solutions started and leads to discover of wide range of antibiotics from microorganisms such as actinomycetes [6, 7]. Thus, the microorganisms have made prominent contributions to the health and well-being of people throughout the world $[8,9]$. Although penicillin was the first antibiotic, discovered by Alexander Fleming in 1928, but it was not until the early 1940s that its true potential was acknowledged and large scale fermentation processes were developed for the production of antibiotics. Waksman and Schatz (1945) isolated streptomycin as a first aminoglycoside against tuberculosis and a number of other antibiotics from Streptomyces griseus [10, 11]. After the revolution in the "heroic" or "golden era", in the forties and early fifties, when nearly all groups of important antibacterial antibiotics (tetracyclines, cephalosporins, aminoglycosides, and macrolides) were discovered, the story of successfully continued [12]. It seemed that in the fifties and sixties that the main problems of chemotherapy had been solved. During this period the 
discovery of antitumor [13], antiviral and non antibiotic enzyme inhibitory metabolites[14, 15] had just started [16].

In the next period, between seventies and nineties the efficiency of research had decreased because of increase in the cost of research. Despite the high cost of research the number of discovered new compounds still increased and was mainly analogue of known compounds. The scope of search for various bioactive microbial products had, however, broadened. The exploration and wide utilization of antitumor (doxorubicin) and agricultural antibiotics (antiparasitic, monensin, avermectin and glufosinate), the preliminary discoveries and utilization of microbial metabolites in the pharmacological fields (cyclosporin, statins), were important new features [16-18]. After these years, from the nineties, the exponential increase in the number of new metabolites (mainly nonantibiotic compounds, analogous and minor compounds), still continued but the occurrence of new chemical types diminished. Due to urgent clinical needs, the increasing serious problems of chemotherapy (multi drug-resistant strains, reappearing mycobacterium, HIV, etc.), new challenges in the therapy of physiological diseases and in agriculture, the modernization of classical screening methods, allowed by the new technologies, were highly required $[19,20]$. The screenings have become more efficient than ever. The dramatic increase in the isolation of non-antibiotic compounds with activities in pharmacological and agricultural fields increased the share of various fungal metabolites and the chemical synthesis of more intricate structures were the most characteristic features of this period. Although, antibiotics have revolutionized medical care in the $20^{\text {th }}$ century, It seems, with the beginning of the 21 st Century, a new era of antibiotic research had opened $[16,21]$.

The number of antibiotics were known in 1940 about 10 20, in 1950, 300 400, already 800 1000 in 1960 and approximately 2500 till 1970. Since then the number of all known bioactive microbial metabolites had doubled in every ten years. In 1980 about 5,000 and in 1990 about 10,000 antibiotic compounds were known [16]. The results of an extensive research revealed that the total number of antibiotic compounds, recognized until now, is around 25,000 30,000 (Figure 1). Beside plants [22], microorganisms represent a good source of varied antibiotics. As, about 16,500 of antibiotics are extracted from microorganisms. Among them, over 8,700 (53 \%) antibiotics are produced by Actinobacteria, $4,900(30 \%)$ by fungi and 2,900 (18\%) by unicellular bacteria [8, 16]. The Approximate number of known antibiotics produced by living organisms is presented in Table 1. 
Table 1. Approximate number of known bioactive natural products from living organisms

\begin{tabular}{lll}
\hline Source & & Antibiotics \\
\hline Natural Product & & 25000 to 30000 \\
\hline Plant Kingdom & & $\sim 25000$ \\
\hline Microorganisms & Microorganisms & $\sim 16,500$ \\
\cline { 2 - 3 } & Bacteria & 2,900 \\
\cline { 2 - 3 } & Actinomycetes & 8700 \\
\cline { 2 - 3 } & Fungi & 4,900 \\
\hline Algae, Lichens & & $\sim 1000$ \\
\hline Higher Plants & & 10,000 \\
& & to12,000 \\
\hline Animal Kingdom & $\sim 5000$
\end{tabular}

Adopted from

\begin{tabular}{lll}
\hline Protozoa & Berdy, 2005 \\
\cline { 1 - 1 } Invertebrates & $\sim 50$
\end{tabular}

\begin{tabular}{ll}
\hline Marine animals & 3000 to 4000 \\
\hline Insects/Worms/etc & 150 to 200 \\
\hline $\begin{array}{l}\text { Vertebrates(mammals,fishes, } \\
\text { amphibians, etc.) }\end{array}$ & $\sim 1000$ \\
\hline
\end{tabular}

\subsection{Classification of antibiotics}

The great number of diverse antibiotics can be classified in different ways based on microbial spectrum, the type of biological activity and the chemical structure. But they are usually classified based on their structure and/or function [ 1,3,23]. The major classes are as follows:
a) B-Lactams (Penicillins, Cephalosporins, Monobactams and Carbapenems)
b) Aminoglycosides (Streptomycin and Kanamycin)
c) Tetracycline
d) Sulfonamides 
e) Macrolides (Erythromycin and Quinines)

f) Glycopeptides (Vancomycin)

\subsection{Mechanism of antibiotic action}

Antimicrobial agents are broadly classified based on in vitro behavior as microcidal (kill microorganisms directly) or microstatic (simply prevent them from growth). The major modes of action by different antibiotics include [1, 23]:

1) Inhibition of Cell wall synthesis

The antibiotics such as $B-$ lactams (penicillin, cephalosporins) and glycopeptides (vancomycine and teicoplanin) block the ability of bacteria to synthesize their cell wall by inhibiting the synthesis of peptidoglycan.

2) Plasma membrane inhibition

Certain antibiotics, especially polypeptide antibiotics, bring about changes in the permeability of the plasma membrane; these changes result in the loss of important metabolites from the microbial cell. As for example polymixin B binds to the phospholipids of the cell membrane and disrupts its integrity, destroying their ability to function as osmotic barriers.

3) Inhibition of nucleic acid synthesis

A number of antibiotics interfere with nucleic acid metabolism of microorganisms. ciprofloxacine, nalidixic acid, rifamycin, trimethoprime, oxolinic acid, etc. bind to DNA gyrase (topoisomerase) thereby preventing the supercoiling of DNA, and inhibiting DNA synthesis. They are widely used in chemotherapy because they are more selective toxicity.

4) Inhibition of protein synthesis

The ribosomes are the sites of protein synthesis in the bacterial cell. Prokaryotic cells have $70 \mathrm{~S}$ ribosome which is made up $50 \mathrm{~S}$ and $30 \mathrm{~S}$ unit. Antibiotics such as streptomycin, gentamycin, kanamycine, tetracycline, spectinomycine, chloramphenicol, and erythromycin bind to either $50 \mathrm{~S}$ or $30 \mathrm{~S}$ subunit of the ribosome or to mRNA and impair the functioning. There by inhibiting the synthesis of proteins.

5) Inhibition of enzymatic activity

Sulfonamides completely inhibit the important metabolic pathways (synthesis of folic acid)occurring inside the bacterial cell. Thus, important metabolites like folic acid, a vitamin that functions as a coenzyme for the synthesis of the purine and pyrimidine base of 
nucleic acids, which the bacteria have to produce within their cells to survive are not produced.

\section{DRUG RESISTANCE IN MICROBES}

Although, antimicrobial agents represent one of the essential therapeutic tools, both in human and veterinary medicine to control and treat a variety of microbial infectious diseases. However, during the past five decades the use and sometimes misuse of antimicrobials has caused bacterial resistance to currently available antibacterial drugs by either new mutations or the exchange of genetic information that is, placing past resistance genes into new hosts[24].

Several mechanisms of antimicrobial resistance are easily spread to a variety of bacterial genera $[25,26]$ :

A) Genetic resistance: this occurs due to chromosomal mutations or acquisition of antibiotic resistant genes on plasmids or transposons.

B) Phenotypic resistance: this occurs due to changes in bacterial physiological state in stationary phase.

The main phenotypic antimicrobial resistance is as follows:

a) Enzymatic inactivation like B-lactams, Aminoglycosides and Macrolides.

b) Decreased permeability/uptake like $\beta$-lactams and Aminoglycosides

c) Enhanced efflux like Tetracycline, Quinolones and Macrolides.

d) Alteration of drug target site due to change in antibiotic binding target site like of Blactamase, Quinolones, Aminoglycosides, Vancomycin, Macrolides and TMP/ SMX.

\section{NEW CHALLENGES IN ANTIBIOTICS}

Today, over 30,000 clinical diseases described. Under a third of these could be treated symptomicaly and just a few can be cured. Despite the developments and progress made in modern medicine, science and biotechnology, infectious diseases are still the second leading cause of death worldwide [27, 28]. It is an epidemic of multiple antibiotic resistance in pathogens has been described in various fields, including but not limited to a global pandemic of methicillin-resistant Staphylococcus aureus (MRSA) infection [29]. The global spread of antibiotic resistance properties among common respiratory pathogens such as Streptococcus pneumoniae and Mycobacterium tuberculosis and epidemic in 
Vancomycin Resistant Enterococci (VRE), Pseudomonas aeruginosa and Candida albicans, etc. Infections caused by these and other antibiotic-resistant microorganisms have given effect and significant impact on morbidity and mortality, which has become a major clinical and public health problem in the 21st century [30-32]. According to World Health Organization (WHO), over-prescription and incorrect use of antibiotics leads to the generation of antibiotic resistance in many human pathogens. The slogan of WHO in 2011 was "multi- drug resistant pathogens have become a major global healthcare threat" [21]. Moreover, the undesirable side effects and toxicity of some used antibiotics (Ningthoujam et al, 2009), non-cultivable of some species of potent bacteria [33] and the exhaustion of the natural sources dictate an increasing necessity of survey for unexplored and under-explored niche habitats for the isolation and discovery of natural product-based drugs with broad-spectrum which possess different mechanisms of action and which are free from undesirable side effects (safe) [24] Such things be developed as part of the strategy to control the emerging drug-resistant pathogens in research programs around the world [32, 34-36]. Hence, there is a need for more and more screening programs in isolation of new potent organisms and novel antimicrobial metabolites from newer ecosystem for potential pharmaceutical, agriculture and industrial applications around the world [37-45].

\section{CONCLUSION}

Antibiotics are secondary metabolites with powerful therapeutic activity which are produced by potent living organisms. In recent times, the drug resistant strains of microorganisms emerge more quickly than the rate of discovery of new drugs and antibiotics. Hence the search for isolating novel antibiotics continues to be of immense importance in research programs around the world for pharmaceutical, industrial and agricultural applications.

\section{FINANCIAL SUPPORT}

Nil.

\section{CONFLICTS OF INTEREST}

There are no conflicts of interest. 


\section{REFERENCES}

[1] Walsh C. Antibiotics. Am. Soc. Microbiol., 2003a.

[2] Lorian, V. (Ed.). Antibiotics in laboratory medicine, Lippincott Williams \& Wilkins Company, 2005.

[3] Korzybski T, Kowszyk-Gindifer Z, Kurylowicz W. Antibiotics: origin, nature and properties, Elsevier, 2013.

[4] Demain AL. Pharmaceutically active secondary metabolites of microorganisms. Appl. Microbial, Biotechnol., 1999, 1,52(4), 455-63.

[5] Quigley EM, Quera R. Small intestinal bacterial overgrowth: roles of antibiotics, prebiotics, and probiotics. Gastroenterol., 2006, 130(2)S, 78-90.

[6] Baltz RH. Antimicrobials from actinomycetes: back to the future. Microbe-Am Soc. Microbiol., 2007, 2(3), 125-131.

[7] Dharmaraj S. Marine Streptomyces as a novel source of bioactive substances. World J. Microbiol Biotechnol. 2010., 26(12), 2123-39.

[8] Demain AL, Sanchez S. Microbial drug discovery: 80 years of progress.J. Antibiot., 2009, 62(1), 5-16.

[9] Omura S. (Ed.). The search for bioactive compounds from microorganisms, Springer Science \& Business Media, 2012.

[10] Waksman SA, Schatz A. Streptomycin-origin, nature, and properties. J. Am. Pharm. Assoc. 1945, 34(11), 273-91.

[11]Williams ST. Genus Streptomyces waksman and henrici 1943. Bergey's Manual of Syntematic Bacteriology. Williams and Wilkins Company, Baltimore, 1989, 2452-2492.

[12] Clardy J, Fischbach MA, Walsh CT. New antibiotics from bacterial natural products, Nat. Biotechnol., 2006, 24(12), 41-50.

[13] Olano C, Méndez C, Salas JA. Antitumor compounds from marine actinomycetes. Mar. Drugs., 2009, 7(2):210-48.

[14]Pecznska-Czoch, W And Mordarski, M. Actinomycete enzymes. In: M.Goodfellow, S. T. Williams, and M. Mordarski (Eds.), Actinomycetes in Biotechnology, Academic Press Limited, London,1988, 219-283.

[15]Huneck S. The significance of lichens and their metabolites, Naturwissenschaften, 1999, 86(12):559-70.

[16] Janos Berdy, J. Bioactive microbial metabolites. J. Antibiot., 2005, 58, 1-26. 
[17]Lancini G, Demain AL. Bacterial pharmaceutical products. InThe prokaryotes, Springer Berlin Heidelberg, 2013, 257-280.

[18]Demain AL. Importance of microbial natural products and the need to revitalize their discovery. J. Ind. Microbiol. Biotechnol., 2014, 41(2), 185-201.

[19]Finch R. Bacterial resistance-the clinical challenge. Clin. Microbiol. Infec, 2002, 8(s3), 21-32.

[20]Norrby SR, Nord CE, Finch R. Lack of development of new antimicrobial drugs: a potential serious threat to public health. Lancet Infect. Dis., 2005, 5(2):115-9.

[21] Alanis AJ. Resistance to antibiotics: are we in the post-antibiotic era?. Arch. Med. Res., 2005, 36(6):697-705.

[22] Abdallah EM. Plants: An alternative source for antimicrobials. J. Appl. Pharm. Sci. 2011, 1(6):16-20.

[23] Tortora GJ, Funke BR, Case CL. Microbiology: An Introduction. Pearson Education, Inc., India, 2009.

[24] Walsh C. Where will new antibiotics come from?, Nat. Rev. Microbiol., 2003, 1(1):6570.

[25] Sefton AM. Mechanisms of antimicrobial resistance, Drugs, 2002, 62(4):557-66.

[26] Tenover FC. Mechanisms of antimicrobial resistance in bacteria, Am. J. Med., 2006, 119(6):S3-10.

[27]Luzhetskyy A, Pelzer S, Bechthold A. The future of natural products as a source of new antibiotics, Curr. Opin. Invest. Drugs, 2007, 8(8):608-13.

[28]Kumar R, Yadav BR, Singh RS. Antibiotic resistance and pathogenicity factors in Staphylococcus aureus isolated from mastitic Sahiwal cattle. J. Biosci., 2011 , 36(1):17588.

[29] Baquero F. Gram-positive resistance: challenge for the development of new antibiotics. J. Antimicrob. Chemoth., 1997, 39(1):1-6.

[30]Quadri LE. Strategic paradigm shifts in the antimicrobial drug discovery process of the 21st century. Infect. Disord. Drug Targets, 2007, 7(3):230-7.

[31] Spellberg B, Guidos R, Gilbert D, Bradley J, Boucher HW, Scheld WM, Bartlett JG, Edwards J, Infectious Diseases Society of America. The epidemic of antibiotic-resistant infections: a call to action for the medical community from the Infectious Diseases Society of America. Clin. Infect. Dis., 2008, 46(2):155-64. 
[32] Piddock LJ. The crisis of no new antibiotics-what is the way forward?. Lancet Infect. Dis., 2012, 12(3):249-53.

[33]Ling LL, Schneider T, Peoples AJ, Spoering AL, Engels I, Conlon BP, Mueller A, Schäberle TF, Hughes DE, Epstein S, Jones M. A new antibiotic kills pathogens without detectable resistance. Nature, 2001, 517(7535), 455-9.

[34]Wise R, Hart T, Cars O, Streulens M, Helmuth R, Huovinen P, Sprenger M. Antimicrobial resistance is a major threat to public health. Brit. Med. J., 1998, 317(7159):609-11.

[35]Projan SJ. New (and not so new) antibacterial targets-from where and when will the novel drugs come?. Curr. Opin. Pharmacol., 2002, 2(5):513-22.

[36]Livermore DM, Blaser M, Carrs O, Cassell G, Fishman N, Guidos R, Levy S, Powers J, Norrby R, Tillotson G, Davies R. Discovery research: the scientific challenge of finding new antibiotics. J. Antimicrob. Chemoth., 2011, 1941-1944.

[37]Laidi RF, Elshafei A, Sanker M, Cheick B, Hocine H. Screening, isolation and characterization of a novel antimicrobial producing actinomycetes, strain RAF10. Biotechnol. 2007, 6, 489-96.

[38]Awad MH, El-Shahed KY, El-Nakkadi AE. Isolation, screening and identification of newly isolated soil Streptomyces (Streptomyces sp. NRC-35) for $\beta$-lactamase inhibitor production, World Appl. Sci. J., 2009, 7(5), 637-46.

[39] Naikpatil SV, Rathod JL. Selective isolation and antimicrobial activity of rare actinomycetes from mangrove sediment of Karwar, J. Ecobiotechnol., 2011, 28, 3(10).

[40] Raja A, Prabakarana P. Actinomycetes and drug-an overview. Am.J. Drug Discov. Dev., 2011, 1:75-84.

[41] Goodfellow M, Stach JE, Brown R, Bonda AN, Jones AL, Mexson J, Fiedler HP, Zucchi TD, Bull AT. Verrucosispora maris sp. nov., a novel deep-sea actinomycete isolated from a marine sediment which produces abyssomicins. Antonie Van Leeuwenhoek., 2012, 101(1):185-93.

[42] Khandan ND, Janardhana GR. Diversity and antimicrobial activities of actinomycetes isolated from soil samples of Kodagu, Karnataka state (India). Int. J. Microbiol. Res., 2013, 5(3):404-9.

[43] Gangwar M, Dogra S, Gupta UP, Kharwar RN. Diversity and biopotential of endophytic actinomycetes from three medicinal plants in India, Afr. J. Microbiol. Res., 2014, 8(2):184-91. 
[44] Saxena S, Meshram V, Kapoor N. Muscodor tigerii sp. nov.-Volatile antibiotic producing endophytic fungus from the Northeastern Himalayas. Ann. Microbiol., 65(1):47-57.

[45]Dezfully NK, Ramanayaka JG. Isolation, Identification and Evaluation of Antimicrobial Activity of Streptomyces flavogriseus, strain ACTK2 from Soil Sample of Kodagu, Karnataka State (India). Jundishapur J. Microbiol., 2015, 8(2).

\section{How to cite this article:}

Khandan Dezfully N and Heidari A. Natural bioactive compounds: antibiotics. J. Fundam. Appl. Sci., 2016, 8(2S), 674-684. 